\title{
Problemzonen? Nein, Danke!
}

\author{
YOGA bei Gesundheitsproblemen - Yoga bietet viele übungen, die den unteren \\ Rücken, Bauch und Oberschenkel stärken, dabei Haltung und Aussehen verbessern \\ und Kraft und Selbstvertrauen aufbauen. Und anstatt über Problemzonen zu lamentieren \\ und zu (selbst)kritisch zu sein, ist es allemal besser, seine Energie ins üben zu stecken.
}

(1)

Wenn die Wirbelsäule bauchwärts gebeugt wird, führen wir eine Vorbeuge aus. Die meisten Vorbeugen erfolgen aus dem Stand: Vorneigen und Hände schütteln, einen Gegenstand vom Tisch aufheben, in ein Auto einsteigen etc. Auf den Fotos zeigen wir eine Vorbeuge aus der Rückenlage. Der Rücken liegt gestreckt am Boden, die Beine werden in Richtung Oberkörper bewegt und der untere Teil der Wirbelsäule hebt sich leicht bauchwärts vom Boden ab. Beim Üben in der Rückenlage ist sichergestellt, dass der Rücken vom Steißbein bis zur Halswirbelsäule gestreckt bleibt. Auf die Streckung Ihres Nackens sollten Sie selbst ganz bewusst achten.

\section{Schnelle Wirkung}

Der angelehnte Stuhl: Mit gestrecktem Rücken aufrecht gegen die Wand lehnen und die Arme neben dem Körper hängen lassen. Den Kontakt des Körpers, von den Schultern bis zum Steißbein, mit der Wand spüren. Den Nacken bewusst strecken und die Kontaktfläche des Kopfes mit der Wand wahrnehmen. Langsam mit den Füßen nach vorn gehen und den
Rücken an der Wand entlang tiefer rutschen lassen. So weit tiefer gehen, dass der Rücken noch Kontakt zur Wand hat. Das Maximum ist erreicht, wenn die Oberschenkel parallel zum Boden sind. Darauf achten, dass die Kniegelenke über den Fußgelenken sind.

Atmen Sie durch die Nase ein und heben Sie dabei Ihre gestreckten Arme vorwärts an bis Ihre Daumen die Wand über Ihrem Kopf berühren. Die Handflächen zeigen zueinander. Darauf achten, dass Ihre Schultern entspannt sind.

Atmen Sie durch die Nase aus und senken Sie dabei Ihre gestreckten Arme zurück in die Ausgangsposition. Die Übung sechsmal wiederholen und Atmung und Bewegung synchron führen. Zum Schluss richten Sie sich wieder auf, stellen sich frei in den Raum und spüren nach.

\section{Anhaltende Wirkung}

Bein- und Armstreckung: Kommen Sie in die Rückenlage und strecken Sie sich komplett am Boden aus (Foto 1). Beugen Sie die Beine und stellen Sie beide Füße auf. Dann ziehen Sie die Beine weiter zu sich heran. Achten Sie darauf, dass Ihr Nacken ganz gestreckt ist. Legen Sie Ihre Arme gestreckt neben Ihrem Körper ab (Foto 2).

Atmen Sie langsam und vollständig durch die Nase ein. Nutzen Sie den ganzen Atemzug und strecken Sie dabei die Beine in Richtung Decke und heben Sie gleichzeitig dazu Ihre Arme bis Ihre Hände oberhalb Ihres Kopfes Kontakt zum Boden haben (Foto 3).

Atmen Sie langsam und vollständig durch die Nase wieder aus und kommen Sie zurück in die Ausgangslage. Wiederholen Sie die Übung mindestens sechsmal. Nach dem Üben stellen Sie zuerst mit der Ausatmung wieder beide Füße auf. Mit der nächsten Ausatmung strecken Sie beide Beine und kommen wieder in die Rückenlage. Spüren Sie der Wirkung dieser kräftigenden Übung nach. Wenn es angenehm für Sie ist, schließen Sie dabei die Augen.

- Prof. Dr. Ingrid Kollak

- Alice-Salomon Fachhochschule Berlin Yoga-Lehrerin BDY/EYU

- Email:kollak@asfh-berlin.de (Betreff: Yoga bei ...)

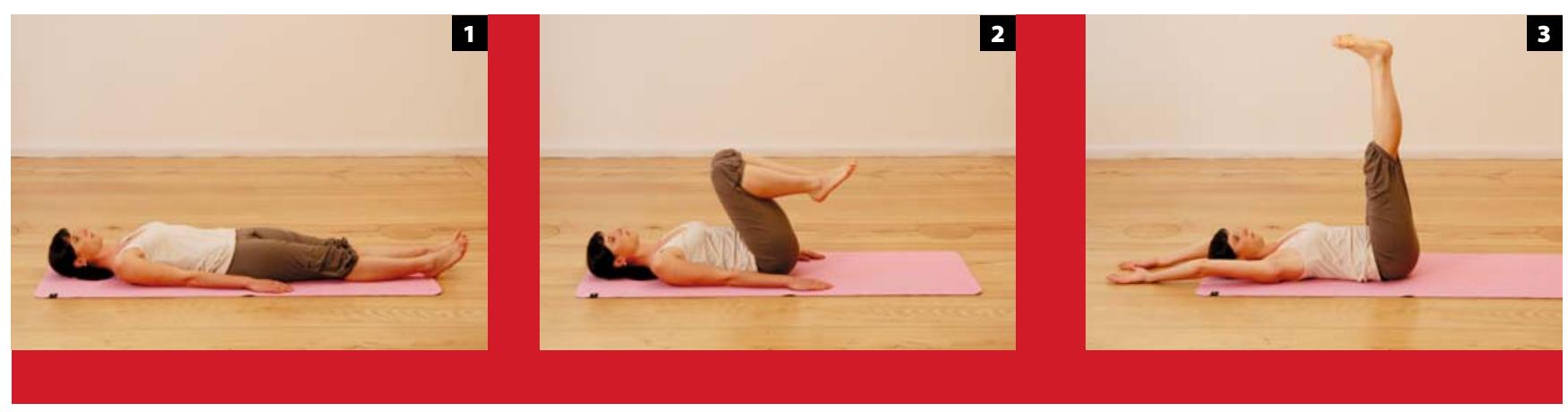

